\title{
Iron Oxide Nanoparticles Coated with Polymer Derived from Epoxidized Oleic Acid and Cis-1,2-Cyclohexanedicarboxylic Anhydride: Synthesis and Characterization
}

\author{
Pereira da Silva S, Costa de Moraes D and Samios D* \\ Laboratory of Instrumentation and Molecular Dynamics, Department of Physical Chemistry, Chemistry Institute, Federal University of Rio Grande do Sul Av. Bento \\ Gonçalves 9500, Porto Alegre, Brazil
}

\begin{abstract}
This study investigated the use of polymer derived from oleic acid for coating iron oxide nanoparticles. The purpose of this study was to provide the magnetic nanoparticles an appropriate surface for stabilization in organic solution. The magnetic nanoparticles coated were produced by mixing of the polymer solution with the ferromagnetic fluid by mechanical stir, followed by magnetic separation. These nanoparticles generated a core-shell behavior, in which the core provides the magnetic properties and the external layer formed by the polymer. The interaction between iron nanoparticles and oleic acid polymer occurred by the affinity of carboxylic group. This interaction makes the nanoparticles hydrophobic, moving to the organic media. The carbon content of the coated nanoparticles was approximately $14 \%$, when analyzed by scattering electron microscopy (SEM-EDX), and $12 \%$, when analyzed by Elemental Analysis of carbon, hydrogen and nitrogen. This percentage confirms the presence of the polymer on the surface of magnetic nanoparticles. The average diameter of the coated and uncoated nanoparticles obtained by transmission electron microscopy was around $13 \mathrm{~nm}$ and $11 \mathrm{~nm}$ and the average diameter of crystallite by $X$-ray diffraction was around $8 \mathrm{~nm}$ and $12 \mathrm{~nm}$ respectively. Averaging all this values we obtain $11 \pm 2 \mathrm{~nm}$. The thermogravimetric analysis showed the degradation temperatures starting from $200^{\circ} \mathrm{C}$ to $500^{\circ} \mathrm{C}$, attributed to the polymer, and another one degradation temperature between $650-750^{\circ} \mathrm{C}$, relative to the polymer-nanoparticles interaction. Furthermore, the vibrating sample magnetometer indicated that coated nanoparticles remain magnetic, with increasing saturation magnetization value, when a magnetic field was applied.
\end{abstract}

Keywords: Magnetic nanoparticles; Iron oxide; Polymers; Oleic acid and cis-1,2-cyclohexanedicarboxylic anhydride

\section{Introduction}

Magnetic materials in nano-scale have been studied because these materials have a diversity of biomedical applications, such as drug delivery in hyperthermia, contrast agents for magnetic resonance imaging (MRI) and bio-separation [1,2]. These magnetic nanoparticles have dimensions of 1 to $100 \mathrm{~nm}$. The particle size depends of the synthesis applied to it and can be controlled by the use of stabilizing agents which act on the surface of the nanoparticles $[3,4]$.

Some preparation methods of magnetic nanoparticles include thermal decomposition [5], microemulsion [6] or co-precipitation $[7,8]$. The co-precipitation method is the simplest and most efficient for obtaining magnetic particles. By this method, the iron oxides $\left(\mathrm{Fe}_{3} \mathrm{O}_{4}\right.$ and $\gamma-\mathrm{Fe}_{2} \mathrm{O}_{3}$ ) are prepared from the stoichiometric mixture of aqueous solutions of ferrous and ferric salts in alkaline medium [9]. The chemical reaction of synthesis of magnetite $\left(\mathrm{Fe}_{3} \mathrm{O}_{4}\right)$ can be described according to Equation 1 . However, magnetite is not very stable and can be oxidized when exposed to atmospheric oxygen turning into maghemite $\left(\gamma-\mathrm{Fe}_{2} \mathrm{O}_{3}\right)$, according to Equation 2.

$$
\begin{aligned}
& \mathrm{Fe}^{2+}+\mathrm{Fe}^{+}+8 \mathrm{OH}^{-} \rightarrow \mathrm{Fe}_{3} \mathrm{O}_{4}+4 \mathrm{H}_{2} \mathrm{O} \\
& \mathrm{Fe}_{3} \mathrm{O}_{4}+2 \mathrm{H}^{+} \rightarrow \gamma-\mathrm{Fe}_{2} \mathrm{O}_{3}+\mathrm{Fe}^{2+}+\mathrm{H}_{2} \mathrm{O}
\end{aligned}
$$

In this stage, according to literature $[10,11]$ the oleic acid, in this case the polymer, is used to coat the magnetic nanoparticles due to its surfactant action that generates high affinity to the nano-magnetite. The action of the stabilizer on the surface of the nanoparticles eliminates, in other words cut out the aggregation process caused by magnetic force attraction and Van der Waals forces. Furthermore, this facilitates the stabilization and dispersion of the particles in organic solutions $[2,12,13]$.
Other factors affecting the formation and shape of the nanoparticles as the salts, the $\mathrm{Fe}^{3+} / \mathrm{Fe}^{2+}$ ratio, the reaction temperature and the $\mathrm{pH}$ [14]. These particles are low cost, low toxicity and eco-friendliness. Also, have excellent physical, chemical and magnetic properties as supermagnetism, high surface area, easy separation under an external magnetic field and strong adsorption capacity [15].

Oleic acid has been one of the fatty acids most commonly used for coating of magnetite. The oleic acid is composed by the carboxylic group and the long chain hydrocarbon, $\left(\mathrm{CH}_{3}\left(\mathrm{CH}_{2}\right)_{7} \mathrm{CH}=\mathrm{CH}\left(\mathrm{CH}_{2}\right)_{7} \mathrm{COOH}\right)$ [4]. The carboxylic group interacts with the hydrophilic surface of the iron oxide and makes it hydrophobic by the presence of the long chain fatty acid. The same action is expected by the polymers produced by using oleic acid and different dicarboxylic anhydrides. Polymers that have functional groups $-\mathrm{COOH},-\mathrm{NH}_{2},-\mathrm{OH}$, are also compatible with these particles, increasing electrostatic attraction between them [16]. Among the polymers used for this purpose are the gum arabic, dextran, chitosan, poly(ethylenimine) (PEI) and poly(ethylene glycol) (PEG) [15,17-19]. Recently, different groups work with the polymerization of fatty acids products like oleic acid, linoleic acid and linolenic acid and

*Corresponding author: Samios D, Laboratory of Instrumentation and Molecular Dynamics, Department of Physical Chemistry, Chemistry Institute, Federal University of Rio Grande do Sul Av. Bento Gonçalves 9500, Porto Alegre, Brazil, Tel: 555133089883; E-mail: dsamios@ufrgs.br

Received March 17, 2016; Accepted April 13, 2016; Published April 23, 2016

Citation: Pereira da Silva S, Costa de Moraes D, Samios D (2016) Iron Oxide Nanoparticles Coated with Polymer Derived from Epoxidized Oleic Acid and Cis-1,2-Cyclohexanedicarboxylic Anhydride: Synthesis and Characterization. J Material Sci Eng 5: 247. doi:10.4172/2169-0022.1000247

Copyright: () 2016 Pereira da Silva S, et al. This is an open-access article distributed under the terms of the Creative Commons Attribution License, which permits unrestricted use, distribution, and reproduction in any medium, provided the original author and source are credited. 
Citation: Pereira da Silva S, Costa de Moraes D, Samios D (2016) Iron Oxide Nanoparticles Coated with Polymer Derived from Epoxidized Oleic Acid and Cis-1,2-Cyclohexanedicarboxylic Anhydride: Synthesis and Characterization. J Material Sci Eng 5: 247. doi:10.4172/21690022.1000247

others $[20,21]$. These polymers are synthesized by epoxidition of the double bond of the fatty acids, and subsequent opening of the epoxide ring with use of triethylamine (initiator) and different kind of anhydride, as phtalic, maleic, succinic or cis-1,2-cyclohexanedicarboxylic.

The aim of this study was to prepare magnetic nanoparticles coated with polymer, produced by the reaction between epoxidized oleic acid, cis-1,2-cyclohexanedicarboxylic anhydride and triethylamine, for stabilizing in organic media. This polymer presents a hydrophilic part characterized by the structure of carboxylic group that provide high chemical affinity to the surface of the magnetic nanoparticles. Moreover, the hydrophobic chain is exhibiting a shell behavior and causes the movement of the nanoparticles to organic medium.

\section{Experimental Part}

\section{Material}

The reagents were used as supplied. Ferric chloride $(\mathrm{FeCl} 2 \bullet 4 \mathrm{H} 2 \mathrm{O}$, 99\%), and cloridric acid (99.5\%) were procured from Sigma-Aldrich, (Darmstadt, Germany). Ferric chloride (FeCl3.6H2O, 97\%), ammonium hydroxide ( $\mathrm{NH} 4 \mathrm{OH}$, minimum assay: $24-26 \%$ ), sodium bisulfate $(99 \%)$, anhydrous sodium sulfate $(58,5 \%)$ and triethylamine P.S. (99\%) were obtained from Vetec (Rio de Janeiro, Brazil). Oleic acid P.A, formic acid (85\%), toluene (99.5\%) and hydrogen peroxide $(30 \% \mathrm{w} / \mathrm{w})$ were purchased from Synth (São Paulo, Brazil). Cis-1,2cyclohexanedicarboxylic anhydride (99\%) was purchased from Acros Organics, (Geel, Belgium).

\section{Synthesis of iron oxide nanoparticles}

The magnetic nanoparticles were produced using the coprecipitation method. The synthesis was carried out by mixing a solution of iron (III) chloride hexahydrate and a solution of iron (II) chloride tetrahydrate by alkaline hydrolysis. The molar ratio of Fe (III) and $\mathrm{Fe}$ (II) was 2:1. The solution of $\mathrm{FeCl} 3.6 \mathrm{H} 2 \mathrm{O}$ was prepared by dissolving the reagent in $40 \mathrm{ml}$ of solution of $\mathrm{HCl}(2 \mathrm{~mol} \mathrm{~L}-1)$, while $\mathrm{FeCl} 2.4 \mathrm{H} 2 \mathrm{O}$ was dissolved in $10 \mathrm{ml}$ of solution of $\mathrm{HCl}(2 \mathrm{~mol} \mathrm{~L}-1)$. After, aqueous solution of ammonia to $0.7 \mathrm{~mol} \mathrm{~L}-1$ was added. The products were stirred mechanically for $30 \mathrm{~min}$. The black precipitate formed was washed with distilled water and excess water was dropped by magnetic sedimentation [22]. The sample was heated at $70^{\circ} \mathrm{C}$ for $30 \mathrm{~min}$ to evaporation of traces of ammonia [4]. The black precipitate formed was kept in water (ferrofluid) for later use.

\section{Epoxidation of oleic acid}

The epoxy rings of the oleic acid were produced by the substitution of the double bonds of the oleic acid. Thus, oleic acid was stirred with toluene and formic acid. After that, the hydrogen peroxide was added dropwise to the reaction for $1 \mathrm{~h}$. The molar ratio of hydrogen peroxide/ formic acid/unsaturation was 20/2/1.The reaction continued for 3 hours at $80^{\circ} \mathrm{C}$ [23]. Finally, a solution of sodium bisulfite $10 \%$ was added under stirring for $10 \mathrm{~min}$ at room temperature. The aqueous phase was discarded and the organic phase was separated and washed until the $\mathrm{pH}$ 6.0-7.0. Anhydrous sodium sulfate was added to remove moisture. The system remained at rest overnight. The epoxide was filtered off and the solvent (toluene) was evaporated in rotary evaporator at $80^{\circ} \mathrm{C}[24,25]$. The obtained product was named Epoxidized Oleic Acid (EOA).

\section{Polimerization reaction}

The polymerization process occurred by mixing $20 \mathrm{~g}$ of epoxidized oleic acid, $10 \mathrm{~g}$ of cis-1,2-cyclohexanedicarboxylic anhydride, $160 \mu \mathrm{l}$ of triethylamine (TEA) as initiator. The reactants were stirred for $3 \mathrm{~h}$
$30 \mathrm{~min}$ at $150^{\circ} \mathrm{C}$. The polymer obtained was presented as a yellowish and translucent product $[23,26]$. This material was named as oleic acid polymer (OAP).

\section{Interaction between magnetic nanoparticles and oleic acid polymer}

The magnetic fluid was mixed in the toluene polymer solution. The suspension was mechanically stirred for $1 \mathrm{~h}$ at room temperature. The coated magnetic nanoparticles were separated by magnetic sedimentation. The samples were dried at $70^{\circ} \mathrm{C}$ to constant weight. The resulting product was named Iron oxide nanoparticles-Oleic acid polymer (INP-OAP), as indicated in Figure 1.

\section{Characterization}

The morphological images of the particles were obtained by scanning electron microscopy (SEM) on a JEOL, model JSM 5800 , operating at $20 \mathrm{kV}$ and coupled with energy dispersive X-ray spectroscopy (EDX), model Norman SistemSix. The preparations of samples were carried out by deposition of the nanoparticles, with and without coating, in aluminum holders and subsequent metallization with gold. The average diameter of the particles and nano-scale images were obtained by transmission electron microscopy (TEM) in a Libra microscope, operating at $120 \mathrm{kV}$. The interaction between the magnetic nanoparticles and the polymer was investigated by Fourier Transform Infrared spectroscopy (FTIR) and Thermogravimetric Analysis (TGA). The equipment used for the analysis of infrared spectroscopy was carried out on Shimadzu FTIR-8300. The spectra were obtained by measurements of transmittance in the range 4000$500 \mathrm{~cm}$-1and averaged over 32 scans. The samples were prepared in $\mathrm{KBr}$ pellets. The equipment used for thermogravimetric analysis was a Universal analyzer V2.6D (TA Instruments). Samples $(10 \mathrm{mg}$ ) were heated from room temperature to $900^{\circ} \mathrm{C}$ at a heating rate of $20^{\circ} \mathrm{C} / \mathrm{min}$ under N2atmosphere. The equipment used for the analysis of X-ray diffraction was a X-ray diffractometer of Rigaku brand, model DMAX 2200 , operating at $40 \mathrm{kV}, 17.5 \mathrm{~mA}, 200 \mathrm{~V}$, equipped with copper tube $(\lambda=1.54178 \AA)$. The angular range was set at $20^{\circ}$ to $75^{\circ}$. The magnetic properties were measured from a vibrating sample magnetometer (VSM), Microsensebrand, model EZ9, at room temperature.

\section{Results and Discussion}

The behavior of the iron nanoparticles in water or toluene can be observed in Figure 2. The pure magnetic nanoparticles remain suspended in aqueous medium due the presence of the hydrophilic

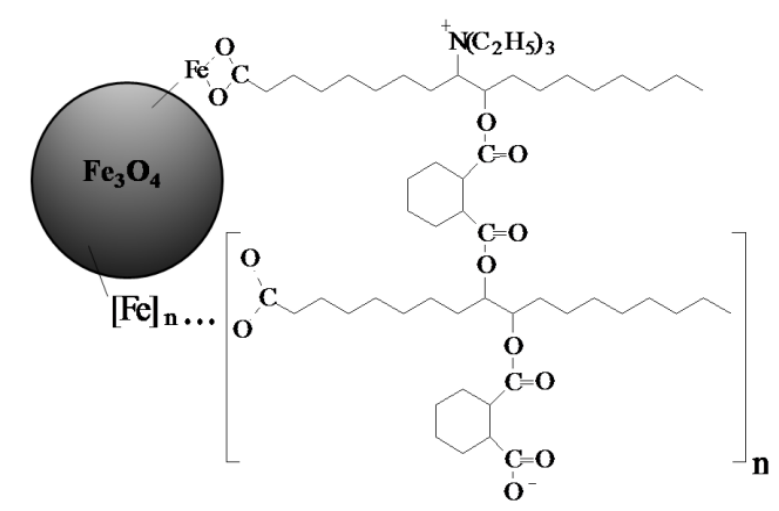

Figure 1: Oleic acid polymer coated magnetite. 

Acid and Cis-1,2-Cyclohexanedicarboxylic Anhydride: Synthesis and Characterization. J Material Sci Eng 5: 247. doi:10.4172/21690022.1000247

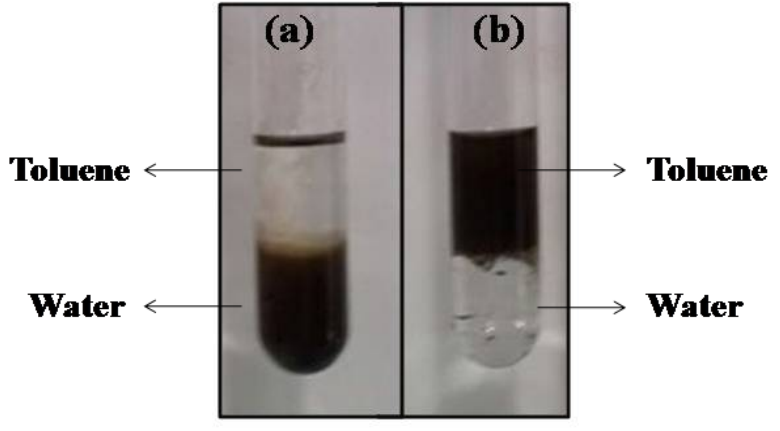

Figure 2: Behavior of the pure nanoparticles (a) and coated nanoparticles (b) in water-toluene system.

surface of the material, as shown in Figure 2a. The Figure $2 \mathrm{~b}$ demonstrates the suspension of iron nanoparticles coated by oleic acid polymer in toluene. As we can see, the coating with polymer makes them to leave from the water in to organic solvent. This stabilization of the modified nanoparticles in toluene confirmed the chemical interaction between the polymer and iron oxide nanoparticles [27].

The Figure 3a shows the SEM images of pure magnetic nanoparticles, Figure $3 \mathrm{~b}$ shows morphology of the polymer and Figure $3 c$ shows nanoparticles coated by the polymer. The corresponding EDX results are presented parallel to these images. The results of percentage of carbon element for nanoparticles uncoated, pure polymer and nanoparticles coated presented values of 1.3, 83.4 and 14.1, respectively. In the case of the iron element the values were 98.7, 16.6 and 85.9, respectively. These results confirm the coating of the nanoparticles by the polymer, because the percentages of carbon, present in chain of the polymer, increased approximately $10 \%$ after coating.

The carbon percent on the surface of the nanoparticles coated was also determined from the elementary analysis of carbon, hydrogen and nitrogen $(\mathrm{CHN})$. This technique showed a percentage of $12.9 \%$ of carbon, $2.4 \%$ of hydrogen and $0.1 \%$ of nitrogen. The carbon content in the sample is derived from oleic acid polymer, confirming the interaction of the nanoparticles with the polymer. The $\mathrm{CHN}$ analysis showed an organic mass content of $19.0 \%$ from the chemical formula of the compound.

The TEM micrographs of the pure nanoparticles and the coated nanoparticles are shown in Figure $4 \mathrm{a}$ and $4 \mathrm{~b}$ respectively, and the respective histograms. The image show that the particles have a reasonably spherical shape, where in the obtained average diameter of the particles was approximately $11 \mathrm{~nm}$ for the uncoated and $14 \mathrm{~nm}$ for the coated, setting them as nanoparticles. However, it is worth to observe that the distribution of the particles is not the same. The coating makes the distribution wider in comparison to the uncoated nanoparticles.

The analysis of X-ray diffraction confirmed the existence of iron oxide particles as shown in Figure $5 \mathrm{a}$. The XRD pattern showed values of $2 \theta$ at $30.3^{\circ}, 35.7^{\circ}, 43.1^{\circ}, 53.6^{\circ}, 57.4^{\circ}$ and $62.6^{\circ}$ concerning plans reflection of the crystal structure of magnetite (220) (311), (400), (440), (531) and (533), respectively [28-30]. The same can be observed for the magnetic nanoparticles coated with polymer (Figure $5 \mathrm{~b}$ ). The broadening of width of half maximum of the peak in the INP-OAP can be seen in all the peaks in the Figure $5 \mathrm{~b}$, as well as the amplified signal relative to the crystallographic plane 311 (Figure 5c).
The average diameter of the crystallites of pure and coated nanoparticles were obtained from the half height of the peaks 311 XRD diffraction and calculated according to the Scherrer equation. The values found were $12 \mathrm{~nm}$ (INP) and $8 \mathrm{~nm}$ (INP-OAP). This difference of the magnitude can be explained by the method used in the preparation of the coated nanoparticles. The coated nanoparticles are submitted in a new heating treatment, which is related to a selective process, selecting the smaller nanoparticles to be coated. However, the process needs more studies. The polymer possesses a lower optical density compared to the pure magnetite, thus, the size of the crystalline refer only to the magnetic core.

The FTIR spectra of Figure 6 shows a comparison of the pure polymer (OAP), the pure nanoparticles (INP) and the iron oxide coated by polymer (INP-OAP). The asymmetric and symmetric stretching of $\mathrm{CH}$ groups present in the polymer chain can be checked at 2925 and $2856 \mathrm{~cm}^{-1}$, respectively [31]. The band at $1724 \mathrm{~cm}^{-1}$ is related to the stretching of the carbonyl group of the carboxylic anhydride and generates an overlapping of peaks $(\mathrm{C}=\mathrm{O})[32,33]$. The band in 1170 $\mathrm{cm}^{-1}$ is a characteristic one for the group C-O-C, present in the ester of the polymer [23]. The nanoparticles of iron oxide (INP) showed bands in the region of 620 and $571 \mathrm{~cm}^{-1}$ characteristic of the $\mathrm{Fe}-\mathrm{O}$ group. The bands at 3400 and $1630 \mathrm{~cm}^{-1}$ assigned to the vibration of $\mathrm{OH}$ group coated on the surface of iron oxide [34]. A shoulder at $1540 \mathrm{~cm}^{-1} \mathrm{can}$ be related to the bond of the carboxylate with the structure of magnetite $[35,36]$. These results confirm the interaction between the oleic acid polymer and the nanoparticles of the Iron oxide [32].

Thermogravimetric analysis was employed to determine the loss of mass of the polymer used in the coating of the nanoparticles (Figure 7). The degradation curve of pure nanoparticles demonstrated a loss percentage of approximately $1 \%$, under the temperature of $100^{\circ} \mathrm{C}$, which can be related to the water adsorbed on the surface of magnetite. In relation to the mass loss of the pure polymer, it was observed two significant losses. The first loss is between $150-300^{\circ} \mathrm{C}$ and the second loss is between $300-400^{\circ} \mathrm{C}$ [32]. This two-step degradation is a characteristic of the polymers produced by plant oils. Observing the mass loss curve of the iron nanoparticles coated with the polymer, we see three degradation stages: the two stages characteristic of the polymer and the third one that is related to the interaction between them, which can be observed at a temperature between $600-800^{\circ} \mathrm{C}[30,37]$.

According to the Figures 8 and 9 , it is possible to make a comparison of the degradation temperature of the pure polymer and coated nanoparticles with it. The two main degradation of the polymer are around 260 and $370^{\circ} \mathrm{C}$ (Figure 8). The Figure 9 indicates in the region between $200^{\circ} \mathrm{C}$ and $500^{\circ} \mathrm{C}$ more than five degradation superposed processes. However, what differentiates the Figures 8 and 9 is the mass loss at temperature $713^{\circ} \mathrm{C}$ and percentage of the loss of $7.55 \%$. This is an additional argument which proves the interaction between iron nanoparticles and polymer obtained using oleic acid.

The presence of magnetic property in the nanoparticles coated was tested by the application of an external magnetic field [38]. The magnetic attraction of these nanoparticles has shown that the magnetic properties are maintained even after coating. This can be seen in Figure 10a where the nanoparticles coated by polymer are suspended in organic phase (toluene), without external magnetic field and Figure $10 \mathrm{~b}$ shows the same composition is suspended under an external magnetic field. It can be observed the attraction of the nanoparticles under the magnetic field.

The magnetic behavior of the Iron oxide nanoparticles and the same nanoparticles coated with the polymer can also be observed 
Citation: Pereira da Silva S, Costa de Moraes D, Samios D (2016) Iron Oxide Nanoparticles Coated with Polymer Derived from Epoxidized Oleic Acid and Cis-1,2-Cyclohexanedicarboxylic Anhydride: Synthesis and Characterization. J Material Sci Eng 5: 247. doi:10.4172/21690022.1000247

(a)

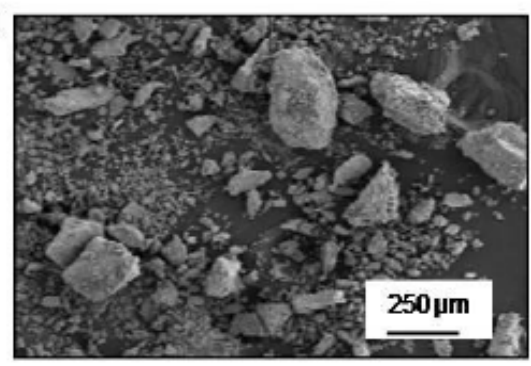

(b)

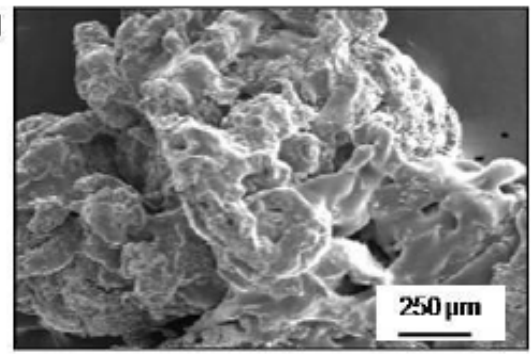

(c)

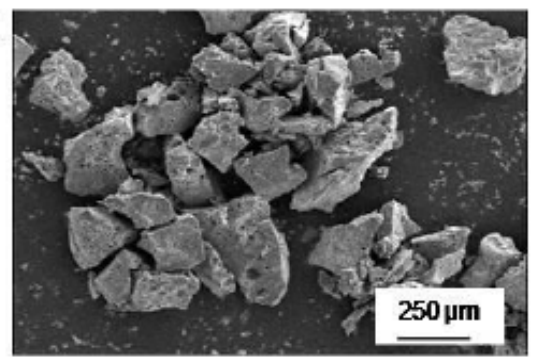

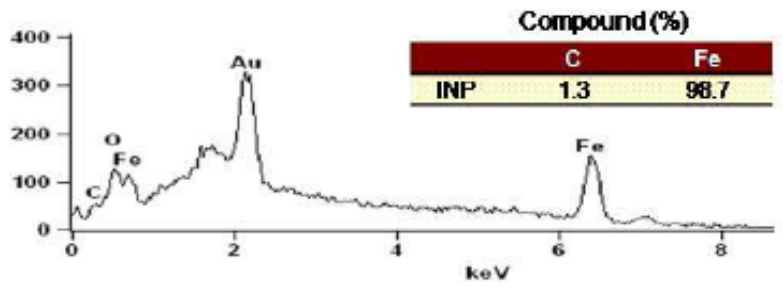
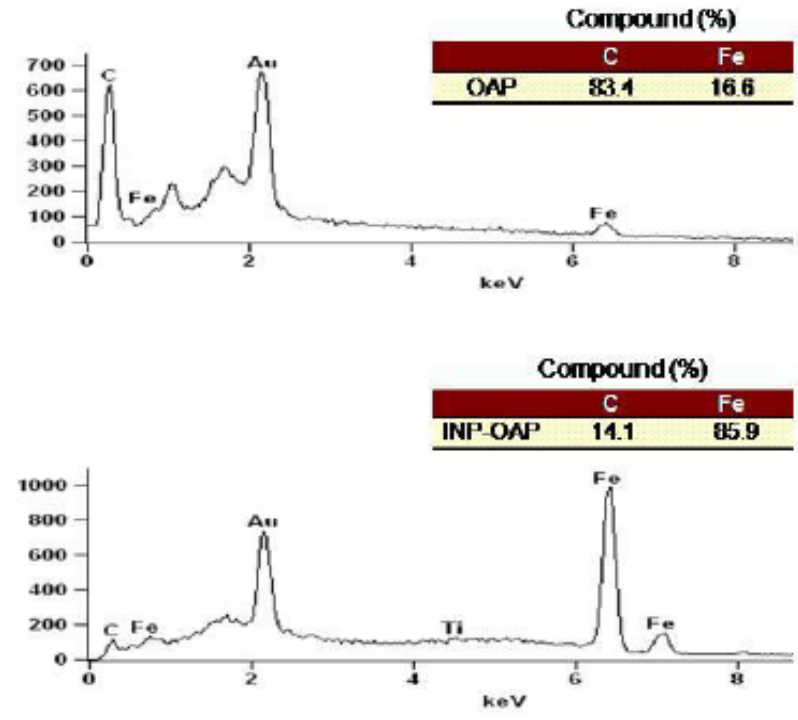

Figure 3: SEM-EDX images: nanoparticles INP (3a), the polymer OAP (3b) and the coated nanoparticles INP-OAP (3c).

(a)
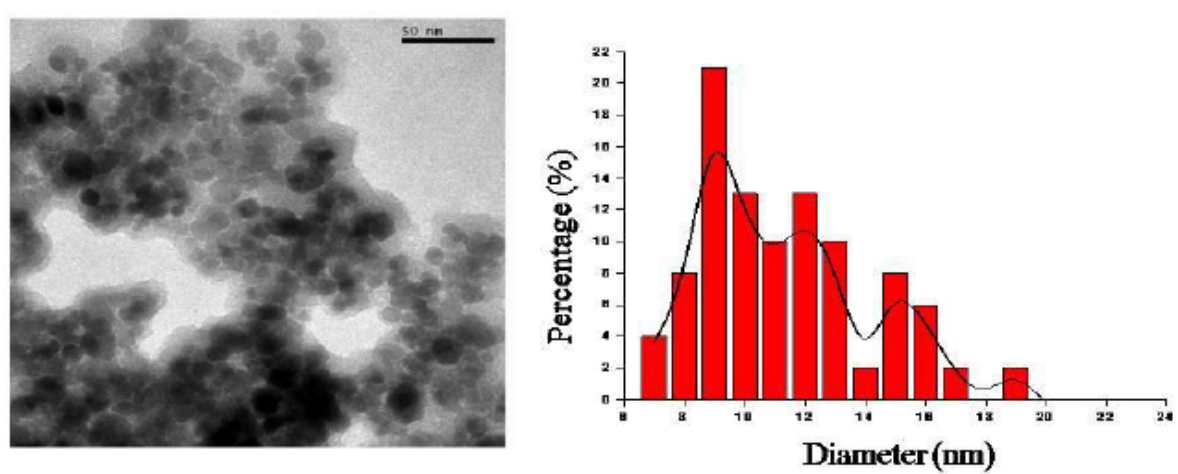

(b)
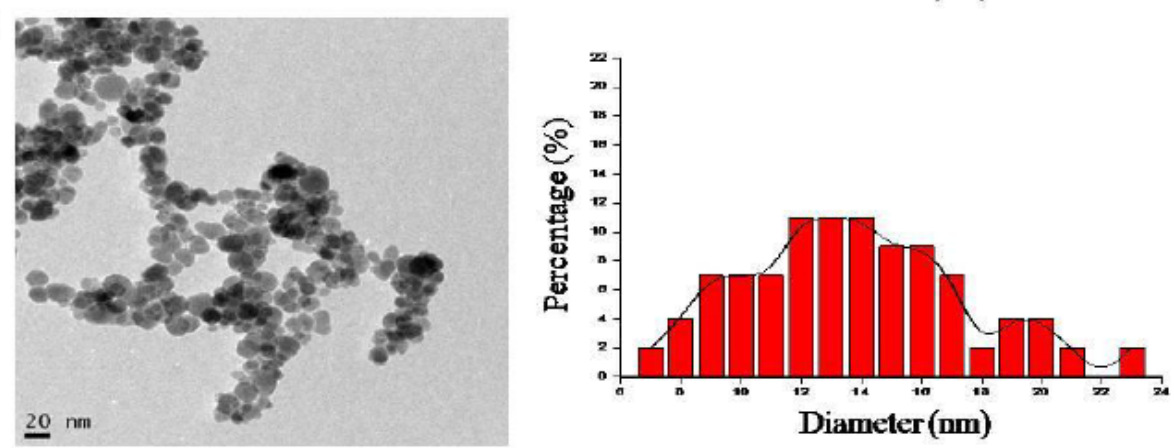

Figure 4: TEM of INP (a), INP-OAP (b) and the histogram of average particle diameters, respectively. 
Citation: Pereira da Silva S, Costa de Moraes D, Samios D (2016) Iron Oxide Nanoparticles Coated with Polymer Derived from Epoxidized Oleic Acid and Cis-1,2-Cyclohexanedicarboxylic Anhydride: Synthesis and Characterization. J Material Sci Eng 5: 247. doi:10.4172/21690022.1000247
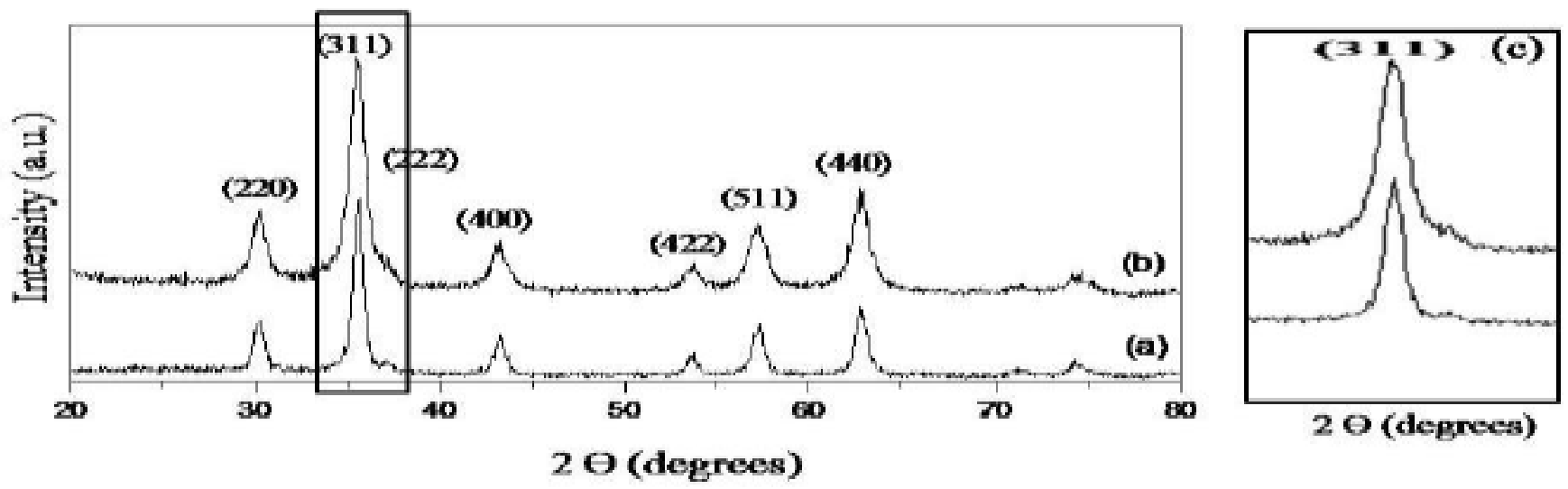

20 (deprees)

Figure 5: The XRD pattern of iron oxide nanoparticles pure (a), iron oxide coated with oleic acid polymer (b) and amplification of the signal 311 (c).

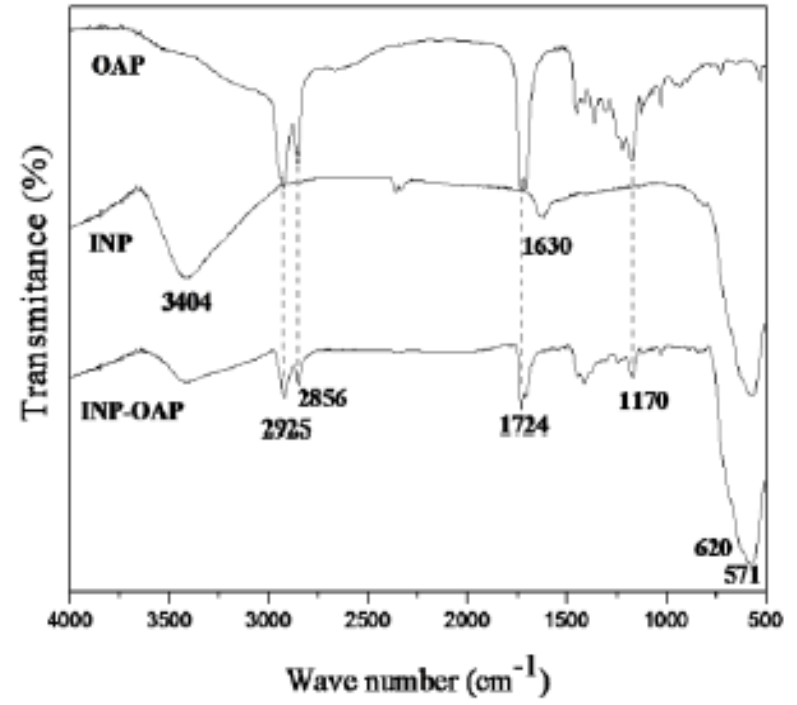

Figure 6: FTIR spectra of iron nanoparticles pure, oleic acid polymer and magnetite coated by OAP.

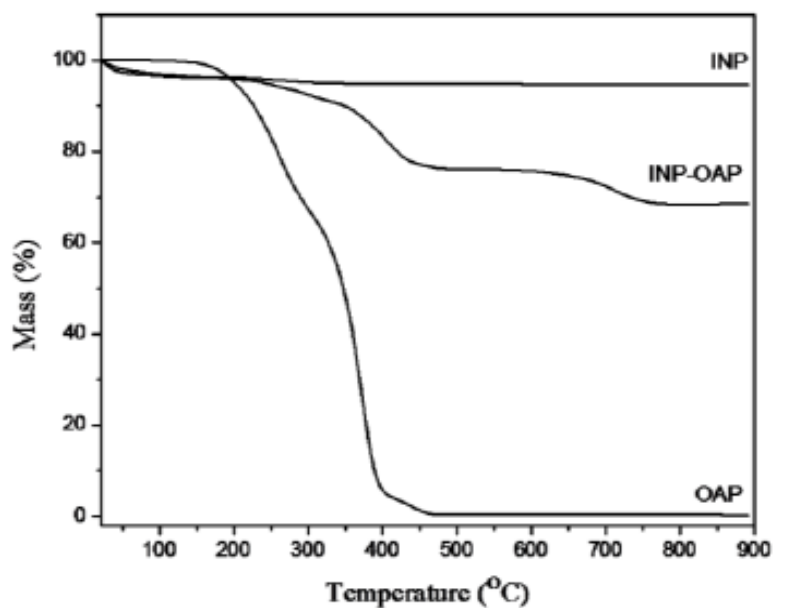

Figure 7: TGA thermograms of Iron nanoparticles (INP), oleic acid polymer (OAP) and the nanoparticles coated by the OAP.

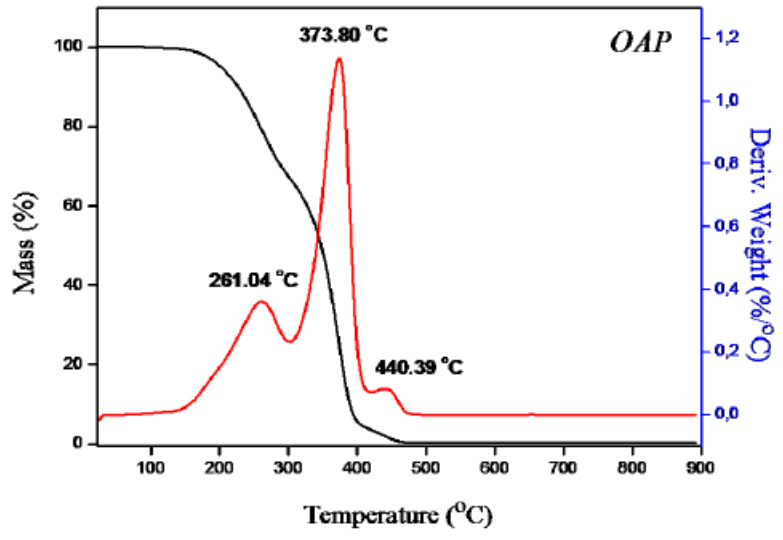

Figure 8: TG-DTA curve of OAP.

from the measurements of the magnetization at room temperature, as shown in Figure 11. According to the magnetization curves could be observed that both of the samples possess typical superparamagnetic behavior. The saturation magnetization of the uncoated particles was $17.7 \mathrm{emu} / \mathrm{g}$ and the corresponding value, for the nanoparticles coated with polymer, was $21.1 \mathrm{emu} / \mathrm{g}$. This can be explained by the size and the broader distribution of the coated the nanoparticles, as well as, the fact that the nanoparticles uncoated when exposed to the environment may undergo oxidation and consequently losing magnetism. The uncoated nanoparticles show smaller diameter and, consequently, smaller protection against oxidation [39].

\section{Conclusion}

Nanoparticles of Iron oxide $\left(\mathrm{Fe}_{3} \mathrm{O}_{4}\right)$ were prepared by using the method of co-precipitation. The prepared nanoparticles were by the coating with a polymer produced by Epoxidized Oleic Acid and cis-1,2cyclohexanedicarboxylic anhydride using triethylamine as initiator.

The core-shell behavior of the coated particles was proved by the stabilization of the nanoparticles in organic medium. By the TEM was possible to obtain particles with diameter average around $11 \mathrm{~nm}$ for the uncoated and around $13 \mathrm{~nm}$ for the coated nanoparticles however with a broader distribution for the second. XRD confirmed the structure of magnetite due to the presence of their crystallographic planes and the same XRD pattern was obtained for the INP-OAP nanoparticles. The 
Citation: Pereira da Silva S, Costa de Moraes D, Samios D (2016) Iron Oxide Nanoparticles Coated with Polymer Derived from Epoxidized Oleic Acid and Cis-1,2-Cyclohexanedicarboxylic Anhydride: Synthesis and Characterization. J Material Sci Eng 5: 247. doi:10.4172/21690022.1000247

Page 6 of 7

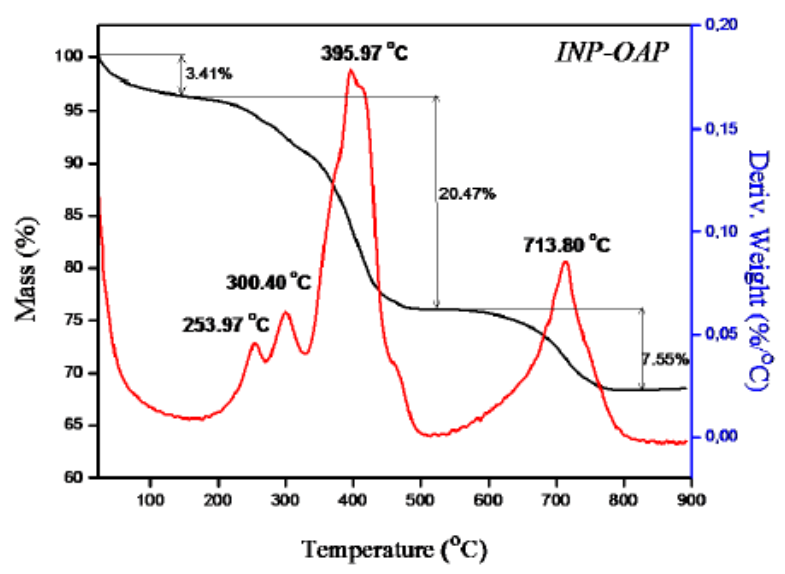

Figure 9: TG-DTA curve of INP-OAP.
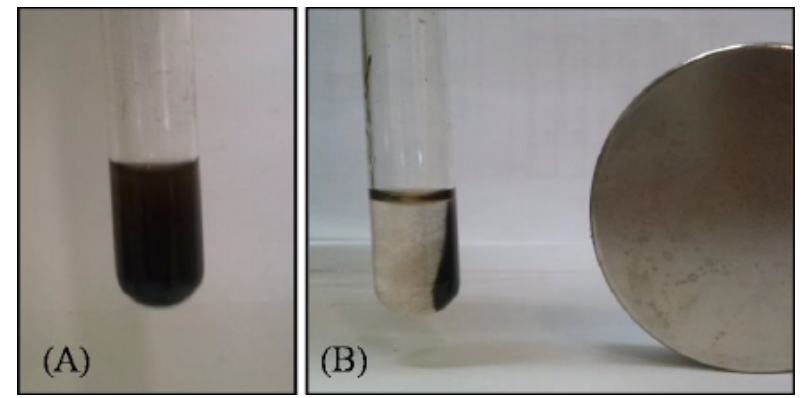

Figure 10: Application of an external magnetic field. (a) INP-OAP in toluene stabilized without external magnetic field and (b) with an external magnetic field.

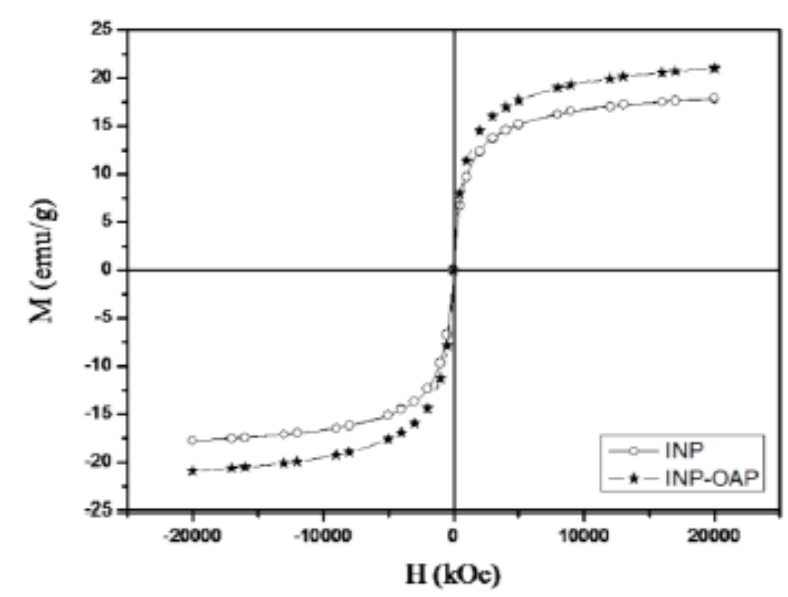

Figure 11: Magnetization (M) versus applied magnetic field $(\mathrm{H})$ for INP and INPOAP, at room temperature.

broadening of the XRD peaks, compared to the magnetite, indicates the interaction between magnetite and polymer. The FTIR of the product polymer-particle showed characteristic bands of separate samples, such as $\mathrm{C}=\mathrm{O}$ and $\mathrm{CH}$, referring to the polymer chain, as well as the $\mathrm{Fe}-\mathrm{O}$, present in the iron oxide. Both materials, uncoated and coated, indicate magnetic properties, however, the magnetization curves showed the presence of superparamagnetic behavior. The coated nanoparticles showed the magnetization value of $21.1 \mathrm{emu} / \mathrm{g}$ and the uncoated the value of $17.7 \mathrm{emu} / \mathrm{g}$.

\section{Acknowledgements}

The authors thank the CNPq (Projects 551116/2010-2 and 405011/2013-0) for financial support, the CNANO (Nanoscience and nanotechnology center) and CME (center of electron microscopy), Federal University of Rio Grande do Sul, Porto Alegre, Brazil, by SEM and TEM images, and the Laboratory of Magnetism, Federal University of Rio Grande do Sul, Porto Alegre, Brazil, for the analyzes of magnetism.

\section{References}

1. Wu Y, Song M, Xin Z, Zhang X, Zhang $Y$, et al. (2011) Ultra-small particles of iron oxide as peroxidase for immune histochemical detection. Nanotechnology 22: 225703.

2. Jadhav NV, Prasad Al, Kumar A, Mishra R, Dhara S, et al. (2013) Synthesis of oleic acid functionalized $\mathrm{Fe}_{3} \mathrm{O}_{4}$ magnetic nanoparticles and studying their interaction with tumor cells for potential hyperthermia applications. Colloids Surfaces B 108: 158-168.

3. Yang TI, Brown RNC, Kempel LC, Kofinas P (2011) Controlled synthesis of core-shell iron-silica nanoparticles and their magneto-dieletric properties in polymer composites. Nanotechnology 22: 105601.

4. Darwish MSA, Peuker U, Kunz U, Turek T (2011) Bi-layered polymer-magnetite core/shell particles: synthesis and characterization. J Mat Sci 46: 2123-2134.

5. Teja AS, Koh PY (2009) Synthesis, properties, and applications of magnetic iron oxide nanoparticles. Prog Cryst Growth Ch 55: 22-45.

6. Wongwailikhit K, Horwongsakul S (2011) The preparation of iron (III) oxide nanoparticles using W/O microemulsion. Mat Lett 65: 2820-2822.

7. Mahdavi M, Ahmad MB, Haron MJ, Namvar F, Nadi B, et al. (2013) Synthesis, Surface Modification and Characterisation of Biocompatible Magnetic Iron Oxide nanoparticles for Biomedical Applications. Molecules 18: 7533-7548.

8. Willard MA, Kurihara LK, Carpenter EE, Calvin S, Harris VG (2004) Chemically preparedmagnetic nanoparticles. Inter Mat Rev 49: 125-170.

9. Kikuchi T, Kasuya R, Endo S, Nakamura A, Takai T, et al. (2011) Preparation of magnetite aqueous dispersion for magnetic fluid hyperthermia. J Magn Magn Mater 323: 1216-1222.

10. Rodríguez C, Bañobre-López M, Kolen'ko $Y$, Rodríguez $B$, Freitas $P$, et al.(2012) Magnetization Drop at High Temperature in Oleic Acid-Coated Magnetite Nanoparticles. IEEE Transactions on Magnetics 48: 3307-3310.

11. Cano M, Sbargoud K, Allard E, Larpent C (2012) Magnetic separation of fatty acids with iron oxide nanoparticles and application to extractive deacidification of vegetable oils. Green Chem 14: 1786-1795.

12. Gyergyek S, Makovec D, Drofenik M (2011) Colloidal stability of oleic- and ricinoleic- acid- coated magnetic nanoparticles in organic solvents. J Colloid Interf Sci 354: 498-505

13. Cohen H, Gedanken A, Zhong ZY (2008) One-Step Synthesis and Characterization of Ultrastable and Amorphous $\mathrm{Fe}_{3} \mathrm{O}_{4}$ Colloids Capped with Cysteine Molecules. J Phys Chem C 112: 15429-15438.

14. Omer M, Haider S, Park SY (2011) A novel route for the preparation of thermally sensitive core-shell magnetic nanoparticles. Polymer 52: 91-97.

15. Laurent S, Forge D, Port M, Roch A, Robic C, et al. (2008) Magnetic Iron Oxide Nanoparticles: Synthesis, Stabilization, Vectorization, Physicochemical Characterizations, and Biological Applications. Chem Rev 108: 2064-2110.

16. Kalska-Szostko B, Wykowska U, Piekut K, Satuła D (2014) Stability of $\mathrm{Fe}_{3} \mathrm{O}_{4}$ nanoparticles in various model solutions. Colloid Surface A 450: 15-24.

17. Kadar E, Batalha IL, Fisher A, Roque ACA (2014) The interaction of polymercoated magnetic nanoparticles with seawater. Science of the Total Environment 487: 771-777.

18. Mahdavi M, Ahmad MB, Haron MJ, Namvar F, Nadi B, et al. (2013) Synthesis of Naphthylpyridines from Unsymmetrical Naphthylheptadiynes and the Configurational Stability of the Biaryl Axis. Molecules 18: 7533-7548.

19. Fathi M, Entezami AA (2014) Stable aqueous dispersion of magnetic iron oxide core-shell nanoparticles prepared by biocompatible maleate polymers. Surf Interface Anal 46: 145-151.

20. Santos EF, Oliveira RVB, Reiznautt QB, Samios D, Nachtigall SMB (2014) Sunflower-oil biodiesel-oligoesters/polytactide blends: Plasticizing effect and ageing. Polym Test 39: 23-29. 
Citation: Pereira da Silva S, Costa de Moraes D, Samios D (2016) Iron Oxide Nanoparticles Coated with Polymer Derived from Epoxidized Oleic Acid and Cis-1,2-Cyclohexanedicarboxylic Anhydride: Synthesis and Characterization. J Material Sci Eng 5: 247. doi:10.4172/21690022.1000247

21. Nicolau A, Samios D, Piatnick CMS, Reiznautt QB, Martini DD, et al. (2012) On the polymerisation of the epoxidized biodiesel: The importance of the epoxy rings position, the process and the products. Eur Polym J 48: 1266-1278.

22. Bruce IJ, Taylor J, Todd M, Davies MJ, Borioni E, et al. (2004) Synthesis, characterization and application of silica-magnetite nanocomposites. J Magn Mater 284: 145-160.

23. Nicolau A, Mariath RM, Martini EA, Martini DS, Samios D (2010) The polymerization products of epoxidized oleic acid and epoxidized methyl oleate with cis-1,2-cyclohexanedicarboxylic anhydride and triethylamine as the initiator: Chemical structures, thermal and electrical properties. J Magn Magn Mater 30: 951-962.

24. Martini DS, Braga BA, Samios D (2009) On the curing of linseed oil epoxidized methyl esters with different cyclic dicarboxylic anhydrides. Polymer 50: 29192925.

25. Reiznautt QB, Garcia ITS, Samios D (2009) Oligoesters and polyesters produced by the curing of sunflower oil epoxidized biodiesel with ciscyclohexane dicarboxylic anhydride: Synthesis and characterization. Mater Sci Eng 29: 2302-2311.

26. Nicolau A, Mariath RM, Samios D (2009) Study of the properties of polymers obtained from vegetable oil derivatives by lightscattering techniques. Mater Sci Eng 29: 452-457.

27. Lee SY, Harris MT (2006) Surface modification of magnetic nanoparticles capped by oleic acids: Characterization and colloidal stability in polar solvents. J Colloid Interf Sci 293: 401-408.

28. Harris LA, Goff JD, Carmichael AY, Riffle JS, Harburn JJ, et al. (2003) Magnetite Nanoparticle Dispersions Stabilized with Triblock Copolymers. Chem Mater 15: 1367-1377.

29. Habibi N (2014) Preparation of biocompatible magnetite-carboxymethy cellulose nanocomposite: Characterization of nanocomposite by FTIR, XRD, FESEM and TEM. Spectrochim Acta A: Molecular and Biomolecular Spectroscopy 131: $55-58$
30. Yang G, Zhang B, Wang J, Xie S, Li X (2015) Preparation of polylysinemodified superparamagnetic iron oxide nanoparticles. J Magn Magn Mater 374: 205-208.

31. Bloemen M, Brullot W, Luong TT, Geukens N, Gils A, et al. (2012) Improved functionalization of oleic acid-coated iron oxide nanoparticles for medical application. J Nanopart Res 14: 1100

32. Zhang L, He R, Gu HC (2006) Oleic acid coating on the monodisperse magnetite nanoparticles. Appl Surf Sci 253: 2611-2617.

33. Lan Q, Liu C, Yang F, Liu S, Xu J, et al. (2007) Synthesis of bilayer oleic acidcoated $\mathrm{Fe}_{3} \mathrm{O}_{4}$ nanoparticles and their application in $\mathrm{pH}$-responsive Pickering emulsions. J Colloid Interf Sci 310: 260-269.

34. Yuen-Jian C, Juan T, Fei X, Jia-Bi Z, Nin G, et al. (2010) Oleic acid were chemisorbed onto the $\mathrm{Fe}_{3} \mathrm{O}_{4}$ nanoparticles as a carboxilate. Drug Dev Ind Pharm 36: 1235-1244.

35. Soares PIP, Alves AMR, Pereira LCJ, Coutinho JT, Ferreira IMM, et al. (2014 Effects of surfactants on the magnetic properties of iron oxide colloids. J Colloid Interf Sci 419: 46-51.

36. Meiorin C, Muraca D, Pirota KR, Aranguren MI, Mosiewicki MA (2014) Nanocomposites with superparamagnetic behavior based on a vegetable oil and magnetite nanoparticles. Eur Polym J 53: 90-99.

37. Zhou J, Fa H, Yin W, Zhang J, Hou C, et al. (2014) Synthesis of superparamagnetic iron oxide nanoparticles coated with a DDNP-carboxyl derivative for in vitro magnetic resonance imaging of Alzheimer's disease. Mater Sci Eng 37: 348-355.

38. Ying XY, Du YZ, Hong LH, Yuan H, Hu FQ (2011) Magnetic lipid nanoparticles loading doxorubicin for intracellular delivery: Preparation and characteristics. J Magn Magn Mater 323: 1088-1093.

39. Daou TJ, Pourroy G, Begin-Colin S, Greneche JM, Ulhaq-Bouillet C, et al (2006) Hydrothermal synthesis of monodisperse magnetite nanoparticles. Chem Mater 18: 4399-4404. 